\title{
Transition-metal-free $\alpha$-arylation of oxindoles via visible-light-promoted electron transfer
}

Cite this: Chem. Sci., 2019, 10, 3049

¿ All publication charges for this article have been paid for by the Royal Society of Chemistry

Received 20th November 2018 Accepted 20th January 2019

DOI: $10.1039 / c 8 s c 05170 d$

rsc.li/chemical-science

\author{
Kangjiang Liang, Na Li, Yang Zhang, Tao Li and Chengfeng Xia (D) *
}

An operationally simple photochemical strategy for the direct arylation of oxindoles with (hetero)aryl halides in the absence of both transition metals and photoredox catalysts has been developed. The reaction provides an efficient way to construct various 3-aryloxindole building blocks of pharmaceutical interest at ambient temperature by using household compact fluorescent light (CFL) bulbs as the light source. Preliminarily, mechanistic studies revealed that the intermolecular electron transfer relied on the formation of photon-absorbing electron-donor-acceptor (EDA) complexes between electron-rich oxindole enolates and electron-deficient (hetero)aryl halides, and a radical chain mechanism was operative.

\section{Introduction}

Oxindoles constitute an essential motif in a wide range of biologically active natural products and a series of pharmaceutically active molecules. ${ }^{1}$ Among them, 3-aryloxindoles are valuable architectures in drug development and display a broad spectrum of biological activities, for instance, as an anticancer agent, ${ }^{2}$ antiproliferative agent, ${ }^{3}$ and neuroprotective agent ${ }^{4}$ (Fig. 1a). In this context, methods for the direct $\alpha$-arylation of oxindoles hold particular promise because of their ability to construct bioactive molecules of pharmaceutical interest.

During the past two decades, the synthesis of 3-aryloxindoles mainly focused on the transition-metal-catalyzed crosscoupling of oxindole cores with various aromatic compounds (Fig. 1b). Significant efforts have been directed towards the development of palladium-catalyzed cross-coupling reactions of oxindoles with aryl halides, ${ }^{5}$ aryl triflates, ${ }^{6}$ aryl tosylates, ${ }^{7}$ or arylboronic acids. ${ }^{8}$ Alternatively, Itami and co-workers provided a nickel-catalyzed method for 3-aryloxindole formation by $\alpha$ arylation of oxindoles with aryl pivalates. ${ }^{9}$ In 2015 , Li and coworkers described an $\mathrm{Fe}(\mathrm{III})$-catalyzed cross-dehydrogenative arylation (CDA) between oxindoles and electron-rich arenes under an air atmosphere. ${ }^{\mathbf{1 0}}$ Additionally, Feng and co-workers reported a scandium(III)-catalyzed $\alpha$-arylation of oxindoles with diaryliodonium salts. ${ }^{\mathbf{1 1}}$ Although significant advances in transition-metal-catalyzed arylation have been made, tremendous challenges still remain with respect to expensive metal catalysts and specific or air-sensitive ligands.

In contrast, transition-metal-free arylations were only limited in the $S_{N} A r$ reaction of oxindoles with electron-deficient nitroaryl

Key Laboratory of Medicinal Chemistry for Natural Resources (Ministry of Education and Yunnan Province), School of Chemical Science and Technology, Yunnan University, 2 North Cuihu Road, Kunming 650091, China. E-mail: xiacf@ynu.edu.cn $\dagger$ Electronic supplementary information (ESI) available: Full experimental procedures and characterisation for all compounds. See DOI: 10.1039/c8sc05170d fluorides $^{\mathbf{1 2}}$ or oxidative nucleophilic addition of oxindoles to nitroarenes. ${ }^{13}$ In addition, Srihari and coworkers reported a multiple aryne insertion approach to construct 3,3-diarylated oxindoles. ${ }^{\mathbf{1 4}}$ Even though the above achievements have been made, the direct $\alpha$-arylation of oxindoles with inactive aryl halides under transition-metal-free conditions remains a challenge.

Recently, visible-light-promoted photochemical transformations by intermolecular electron transfer have received great attention ${ }^{\mathbf{1 5}}$ and (hetero)aryl halides have also been

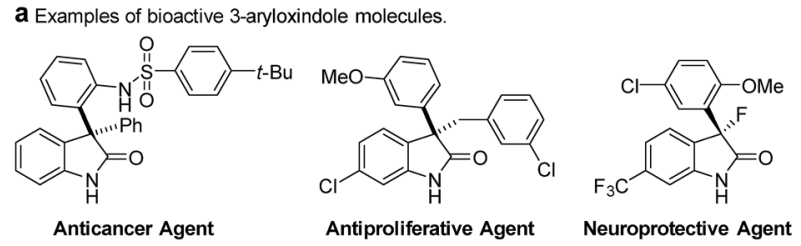

b Transition-metal catalyzed $\alpha$-arylation of oxindoles.
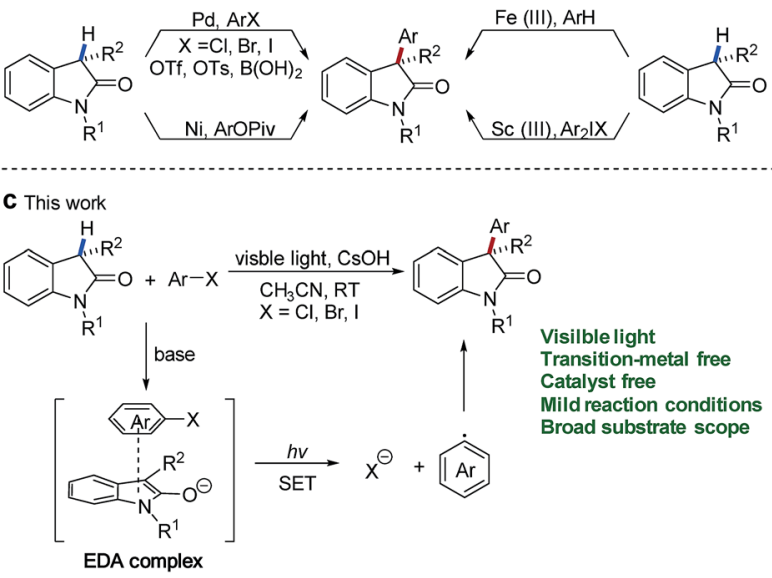

Fig. 1 (a) Pharmaceutically active molecules with a 3-aryloxindole moiety. (b) Transition-metal-catalyzed $\alpha$-arylation of oxindole. (c) Visible-light-promoted arylation of oxindole with an EDA complex. 
disclosed as effective electron acceptors in the thiolate-(hetero) aryl halide EDA complex. ${ }^{16}$ In addition, methods for photoinduced $\mathrm{S}_{\mathrm{RN}} 1$ arylation of ketone enolates by excitation of EDA complexes between ketone enolates and aryl iodides were also reported. ${ }^{17}$ Oxindole enolates are a strong electron donor and have been widely used in SET oxidation reactions. ${ }^{18}$ Inspired by these studies, we questioned whether electron-rich oxindole enolates could act as donors for the formation of EDA complexes with (hetero)aryl halides to realize the direct $\alpha$-arylation of oxindoles under visible-light irradiation. In our design, we envisaged that activation of (hetero)aryl halides might be completed by visible-light-promoted intermolecular electron transfer within the oxindole enolate-(hetero)aryl halide EDA complex (Fig. 1c). The resulting radical anion of (hetero)aryl halide would be able to release a halogen anion to form an electrophilic aryl radical $\left(\mathrm{Ar}^{\circ}\right),{ }^{19}$ which was further trapped by electron-rich oxindole enolate to afford the desired product.

\section{Results and discussion}

\section{Optimization of reaction conditions}

With this design in mind, our initial investigations focused on the cross-coupling between iodobenzene 1a and the oxindole derivative 2a (Table 1). To our delight, when using a household

Table 1 Optimization studies

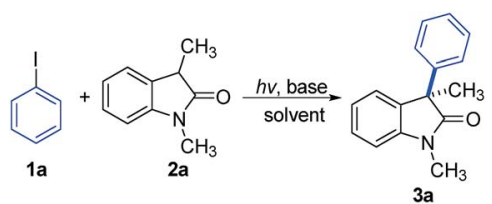

\begin{tabular}{lllll}
\hline Entry $^{a}$ & $h v$ & Base & Solvent & Yield $^{b}(\%)$ \\
\hline 1 & $23 \mathrm{~W} \mathrm{CFL}$ & $\mathrm{CsOH}^{c}$ & $\mathrm{DMSO}$ & 52 \\
2 & $30 \mathrm{~W}$ white LED & $\mathrm{CsOH}$ & $\mathrm{DMSO}$ & 46 \\
3 & $23 \mathrm{~W} \mathrm{CFL}$ & $\mathrm{CsOH}$ & $\mathrm{DMF}$ & 38 \\
4 & $23 \mathrm{~W} \mathrm{CFL}$ & $\mathrm{CsOH}$ & $\mathrm{CH}_{3} \mathrm{CN}$ & 85 \\
5 & $23 \mathrm{~W} \mathrm{CFL}$ & $\mathrm{CsOH}$ & $\mathrm{THF}$ & 19 \\
6 & $23 \mathrm{~W} \mathrm{CFL}$ & $\mathrm{CsOH}$ & $\mathrm{DCM}$ & 0 \\
7 & $23 \mathrm{~W} \mathrm{CFL}$ & $t \mathrm{BuOK}$ & $\mathrm{CH}_{3} \mathrm{CN}$ & 55 \\
8 & $23 \mathrm{~W} \mathrm{CFL}$ & $t \mathrm{BuONa}$ & $\mathrm{CH}_{3} \mathrm{CN}$ & 21 \\
9 & $23 \mathrm{~W} \mathrm{CFL}$ & $t \mathrm{BuOLi}$ & $\mathrm{CH}_{3} \mathrm{CN}$ & 0 \\
10 & $23 \mathrm{~W} \mathrm{CFL}$ & $\mathrm{KOH}$ & $\mathrm{CH}_{3} \mathrm{CN}$ & 62 \\
11 & $23 \mathrm{~W} \mathrm{CFL}$ & $\mathrm{NaOH}$ & $\mathrm{CH}_{3} \mathrm{CN}$ & 15 \\
12 & $23 \mathrm{~W} \mathrm{CFL}$ & $\mathrm{LiOH}$ & $\mathrm{CH}_{3} \mathrm{CN}$ & 0 \\
\hline
\end{tabular}

Entry $^{a} \quad$ Change from the best conditions (entry 4) $\quad$ Yield $^{b}(\%)$

$\begin{array}{lll}13 & \text { No base } & 0 \\ 14 & \text { No light } & 0 \\ 15 & \text { No light and heating to } 80{ }^{\circ} \mathrm{C} & 0 \\ 16 & \text { Bromobenzene instead of iodobenzene } & 51 \\ 17 & \text { Chlorobenzene instead of iodobenzene } & 34\end{array}$

${ }^{a}$ Reaction conditions: 1 equiv. aryl halide, 2 equiv. oxindole, and 3 equiv. base $[0.1 \mathrm{M}]$; all solvents were rigorously degassed by freeze/ pump/thaw. ${ }^{b}$ Isolated yields obtained by chromatography. ${ }^{c} \mathrm{CsOH} \cdot \mathrm{H}_{2} \mathrm{O}$ is abbreviated as $\mathrm{CsOH}$.
$23 \mathrm{~W}$ compact fluorescent light (CFL) bulb to irradiate a DMSO solution of iodobenzene and $2 \mathrm{a}$ in the presence of $\mathrm{CsOH}$ as the base, we observed that the desired $\alpha$-arylation product 3a was obtained in a moderate yield of $52 \%$ at room temperature (entry 1). Conduction of the experiments under illumination with a $30 \mathrm{~W}$ white LED resulted in a slight reduction of the yield (entry 2). Among the solvents screened (entries 3-6), acetonitrile was most efficient for this reaction, and the desired product was obtained in $85 \%$ yield (entry 4). Evaluating various alkoxide/ hydroxide bases indicated that bases with larger radius alkali metal cations, such as $\mathrm{Cs}^{+}$or $\mathrm{K}^{+}$, provided the arylation product in moderate to good yields (entries 4, 7, and 10), whereas bases with $\mathrm{Na}^{+}$or $\mathrm{Li}^{+}$gave decreased yields or failed to afford any products (entries 8, 9, 11, and 12).

To better understand whether different alkali metal cations affecting reactivity was due to either the deprotonation step or a secondary effect in the electron transfer process, ${ }^{\mathbf{1 6}}$ we recorded the ${ }^{1} \mathrm{H}$ NMR spectra of $2 \mathrm{a}$ with different $\mathrm{MOHs}\left(\mathrm{M}=\mathrm{Na}^{+}, \mathrm{K}^{+}\right.$, or $\mathrm{Cs}^{+}$) in $\mathrm{CD}_{3} \mathrm{CN}$. Complete enolate formation of $2 \mathbf{a}$ was observed after treatment with 1.5 equiv. of $\mathrm{MOH}\left(\mathrm{M}=\mathrm{Na}^{+}, \mathrm{K}^{+}\right.$, or $\left.\mathrm{Cs}^{+}\right)$, which demonstrated that all the MOHs could efficiently deprotonate the oxindole (Fig. 2a). Moreover, significant upfield peak shifting of aromatic hydrogens was observed with the magnitude following the order $\mathrm{Cs}^{+}$solution $>\mathrm{K}^{+}$solution $>\mathrm{Na}^{+}$solution (Fig. 2b). These results provided evidence that different alkali metal cations affecting reactivity might be due to a secondary effect in the electron transfer process. The important role of $\mathrm{CsOH}$ was further highlighted by a control experiment which showed that the desired product 3a was not formed in the absence of base (entry 13). Control reactions also revealed the photochemical nature of this transformation, as essentially no $\mathrm{C}-\mathrm{C}$ crosscoupling was observed in the absence of light, even upon heating at $80{ }^{\circ} \mathrm{C}$ (entries 14 and 15). Apart from iodobenzene, bromobenzene and chlorobenzene were also successfully coupled to oxindoles, albeit with lower yields (entries 16 and 17).

\section{Substrate scope}

With the optimum conditions in hand, the scope of the arylation reaction was explored. As illustrated in Table 2, a wide range of (hetero)aryl halides (ArX, where $\mathrm{X}=\mathrm{I}, \mathrm{Br}$, or $\mathrm{Cl}$ ) were successfully employed and they afforded the corresponding 3aryloxindole products in moderate to high yields. First, aryl halides with different substitution patterns, in terms of electronic properties and substitution positions on the aromatic ring, were tested. Under the standard conditions, substrates
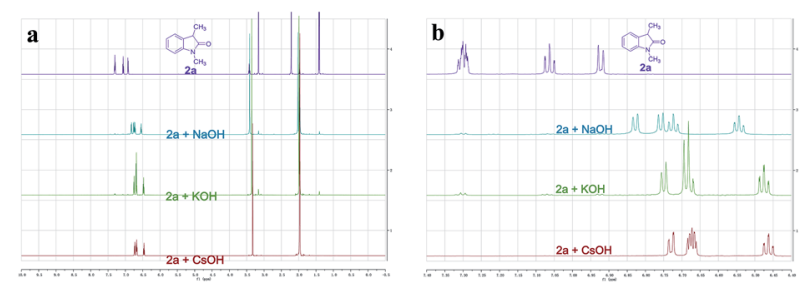

Fig. $2{ }^{1} \mathrm{H}$ NMR spectra of $2 \mathrm{a}$ with different $\mathrm{MOHs}\left(\mathrm{M}=\mathrm{Na}^{+}, \mathrm{K}^{+}, \mathrm{or} \mathrm{Cs}^{+}\right)$ in $\mathrm{CD}_{3} \mathrm{CN}$. (a) Full ${ }^{1} \mathrm{H}$ NMR spectra. (b) Selected aromatic region of the ${ }^{1} \mathrm{H}$ NMR spectral window between 7.40 and $6.40 \mathrm{ppm}$. 
Table 2 Substrate scope of (hetero)aryl halides ${ }^{a}$

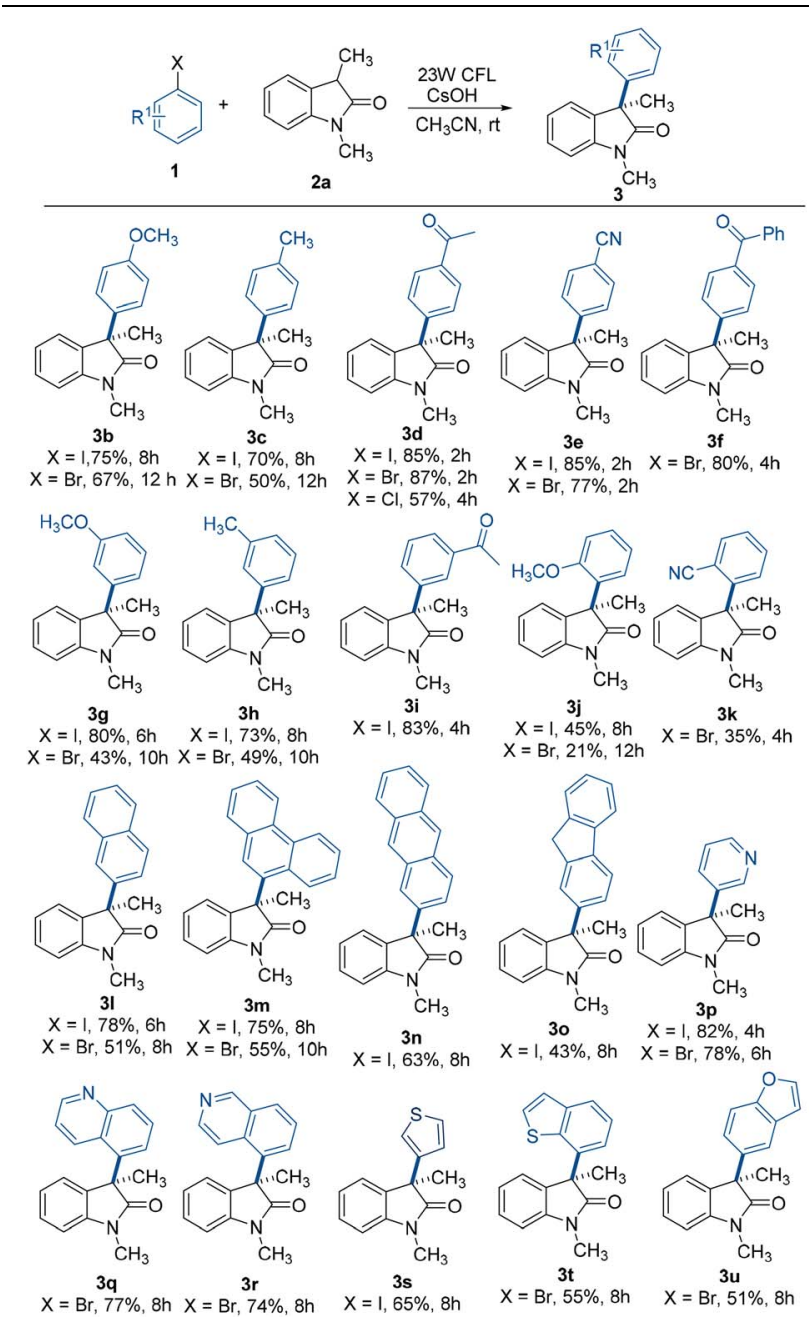

${ }^{a}$ General conditions: $1(0.1 \mathrm{mmol}), 2 \mathrm{a}(0.2 \mathrm{mmol}), \mathrm{CsOH}(0.3 \mathrm{mmol})$, and $\mathrm{CH}_{3} \mathrm{CN}(1.0 \mathrm{~mL})$. Isolated yields are provided.

with electron-rich, electron-neutral or electron-poor substituents positioned para to the halogen proceeded smoothly (3b-3f). Exploration demonstrated that aryl halides with an electron-poor substituent on the aromatic ring gave slightly higher yields than those with electron-rich or electron-neutral substituents. Metasubstituted substrates were also applicable substrates for this photoinduced arylation reaction (3g-3i), whereas substrates with ortho-substituents led to low yields, probably due to the steric hindrance from the substituents ( $\mathbf{3} \mathbf{j}$ and $\mathbf{3 k}$ ). Next, a series of polycyclic aromatic hydrocarbon halides was employed. To our pleasure, polycyclic aromatic hydrocarbons including naphthalene, phenanthrene, anthracene, and fluorene were efficient coupling partners under the optimal conditions (31-3o). Finally, we investigated this arylation reaction involving various heterocycles, which are ubiquitous among pharmaceutical products. Remarkably, heterocycles such as pyridine, quinoline, isoquinoline, thiophene, thianaphthene, and benzofuran also readily participated in the reaction and provided the desired products with acceptable to good yields in this photoinduced system $(3 \mathbf{p}-3 \mathbf{u})$.

To further explore the generality of this reaction, a variety of substituted oxindoles were examined (Table 3). Arylation was explored with an $\mathrm{N}$-unprotected oxindole to provide the corresponding product 4a in 68\% yield. Pleasingly, arylation of other $N$ protected oxindoles (4b $(N$-allyl), 4c $(N$-benzyl), and 4d $(N$-MOM $)$ ) proceeded smoothly and gave satisfying results. Other alkyl groups at the $\mathrm{C} 3$ position were also compatible with this reaction system (4e and $\mathbf{4 f}$ ). It is important to note that tryptophol or tryptamine-containing substrates were well-tolerated, as were those with a 5-methyl or methoxy group, the motifs commonly found in bioactive oxindole-based compounds $(\mathbf{4} \mathbf{g}-\mathbf{4 j}) \cdot{ }^{20}$ Further studies revealed that oxindole substrates containing free amide, hydroxyl, or carboxyl groups $(\mathbf{4 k - 4 m})$ were also tolerated in our reaction system, avoiding the need for protecting groups.

\section{Mechanistic investigation}

To gain further insight into the mechanism of this photoinduced arylation reaction, we performed UV-vis spectroscopic measurements on various combinations of $\mathbf{1 a}, \mathbf{2 a}$, and $\mathrm{CsOH}$ in acetonitrile at a concentration of $0.1 \mathrm{M}$ to investigate the

Table 3 Substrate scope of substituted oxindoles ${ }^{a}$

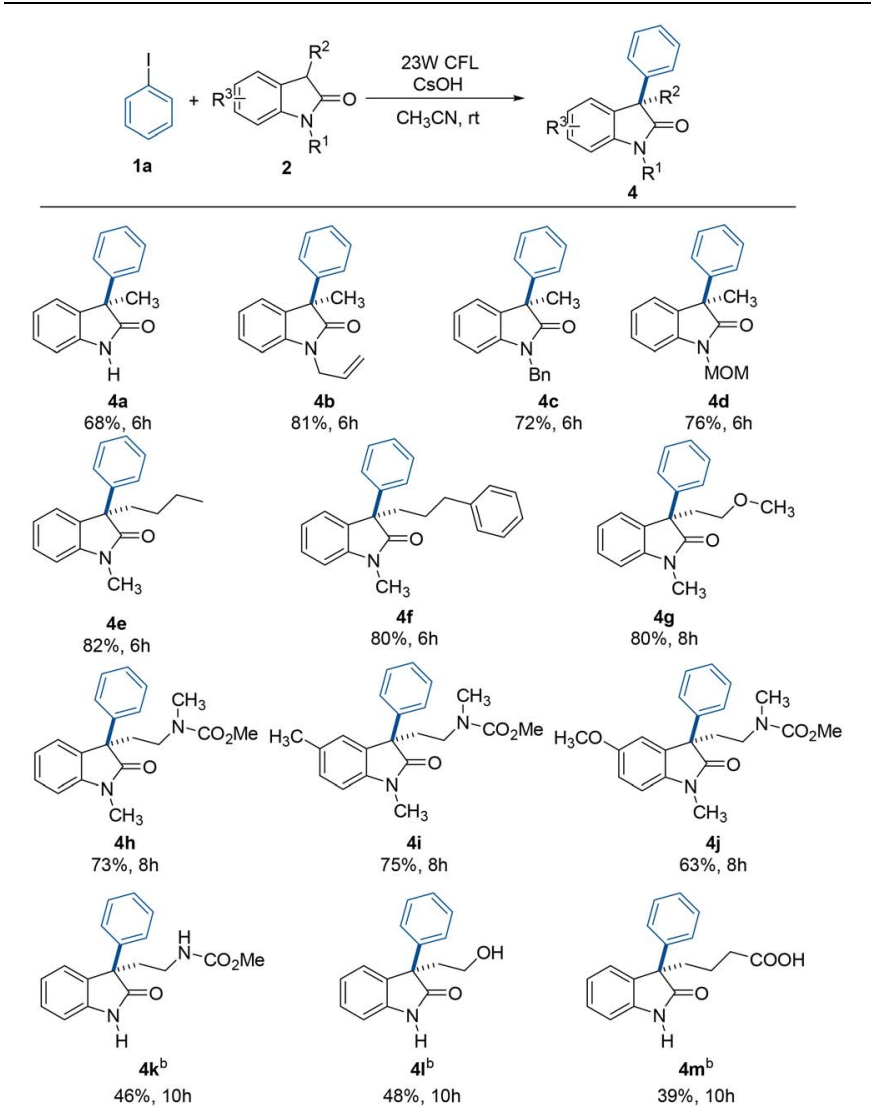

${ }^{a}$ General conditions: $1 \mathrm{a}(0.1 \mathrm{mmol}), 2(0.2 \mathrm{mmol})$, CsOH $(0.3 \mathrm{mmol})$, and $\mathrm{CH}_{3} \mathrm{CN}(1.0 \mathrm{~mL})$. Isolated yields are provided. ${ }^{b}$ Using DMSO instead of acetonitrile as the solvent. 
formation of the proposed EDA complex between iodobenzene 1a and the enolate of $\mathbf{2 a}$. Immediately after mixing an acetonitrile solution of the enolate of $\mathbf{2 a}$, which was in situ generated by the deprotonation of $\mathbf{2 a}$ with $\mathrm{CsOH}$, with iodobenzene 1a, a dramatic color change was observed (Fig. 3a), and this was accompanied by a bathochromic shift in the UV-vis spectra, which is diagnostic of an EDA complex (red line, Fig. 3a). ${ }^{\mathbf{1 5 , 1 6 , 2 1}}$ Interestingly, the absorption spectra of $2 \mathrm{a}$ also show a red shift to the visible region upon $\mathrm{CsOH}$ addition (blue line, Fig. 3a). These results suggested that the enolate of 2a may interact with visible light in two different ways, serving either as a donor in photon-absorbing EDA complex formation or as a photosensitizer upon direct excitation. To elucidate the reaction mechanism, we carried out a control experiment by using a $45 \mathrm{~W}$ white LED lamp, equipped with a band-pass filter at $532 \mathrm{~nm}$ (the enolate of $2 \mathbf{a}$ is unable to absorb at this wavelength, blue line in Fig. 3a), which did not significantly alter the reaction efficiency (Fig. 3b). This result excluded the direct photoexcitation of the enolate of $\mathbf{2 a}$ and suggested that the reaction proceeded likely by the EDA complexdriven photochemical mechanism. ${ }^{15 e, 22}$ A molar donor/acceptor ratio of $1: 1$ for the complex in solution was established by employing Job's method of continuous variation (full details of the stoichiometry determination are reported in ESI note $3 \dagger){ }^{23}$ Additional insight into the mechanism was obtained from an intramolecular radical clock experiment. When the reaction was carried out with substrate $\mathbf{5}$ under standard conditions, the exocyclic product 6 was generated through a 5-exo-trig radical cyclization (Fig. 3c), thereby confirming the radical nature of this reaction. Finally, the quantum yield for the arylation of $2 \mathbf{a}$ was determined to be $\Phi=11.1$ (full details of the quantum yield determination are
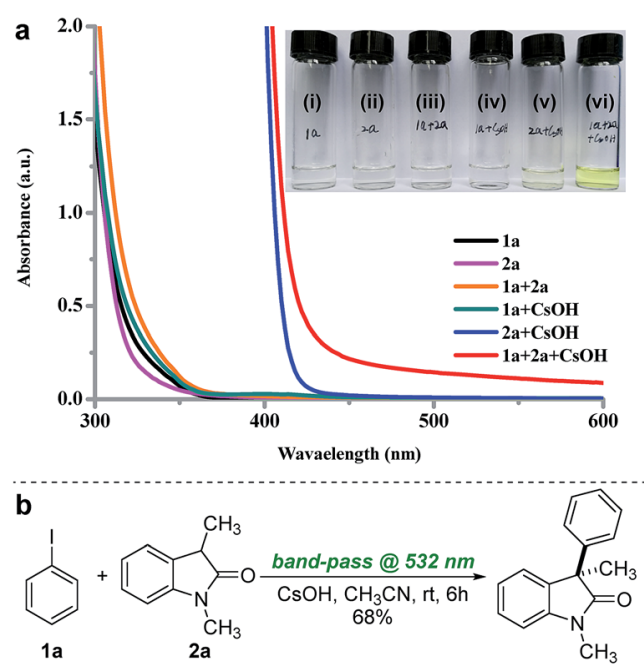

$\mathrm{CH}_{3}$

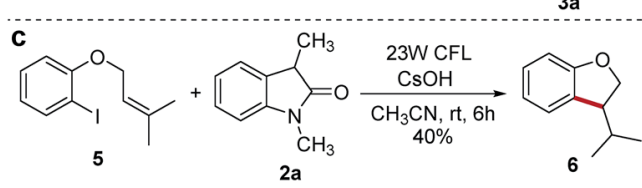

Fig. 3 Mechanistic studies: (a) UV/Vis absorption spectra of acetonitrile solutions ( $0.1 \mathrm{M}$ ) of $1 \mathrm{a}$ (i), $2 \mathrm{a}$ (ii), mixture of $1 \mathrm{a}$ and $2 \mathrm{a}$ (iii), mixture of $1 \mathrm{a}$ and $\mathrm{CsOH}$ (iv), mixture of $2 \mathrm{a}$ and $\mathrm{CsOH}(\mathrm{v})$, and mixture of $1 \mathrm{a}, 2 \mathrm{a}$ and $\mathrm{CsOH}$ (iv). (b) Long wavelength experiment. (c) Intramolecular radical clock experiment. reported in ESI note $6 \dagger$ ), indicating that a radical chain process might be involved in the reaction. ${ }^{15 e, g, 22,24}$

Based on the above observations, a plausible mechanism is outlined in Scheme 1. Initiation of the radical chain begins with the formation of EDA complex $\mathbf{A}$ between the enolate of $\mathbf{2 a}$ and iodobenzene 1a. The photochemical activity of $\mathbf{A}$ triggers a single-electron transfer (SET) to form a radical anion $\mathbf{B}$ and radical C. Fragmentation of the carbon-halogen within $\mathbf{B}$ releases the iodine anion and produces an aryl radical $\mathbf{D}$. The electrophilic aryl radical is next trapped by the electron-rich enolate $\mathbf{E}$ to afford ketyl radical intermediate $\mathbf{F}$, which is a strong single-electron reductant ${ }^{25}$ (the oxidation potential of $\mathbf{F}$ was estimated by measuring the reduction potential of $\mathbf{3 a}$, and no reduction waves were detected for $3 \mathrm{a}$ in the range of $-2.80 \mathrm{~V}-$ $0 \mathrm{~V}$ vs. $\mathrm{Ag} / \mathrm{Ag}^{+}$in $\mathrm{CH}_{3} \mathrm{CN}$, ESI Fig. $\left.5 \dagger\right)$. This cyclic voltammetry result means that ketyl radical intermediate $\mathbf{F}$ can transfer an electron to iodobenzene $1 \mathrm{a}\left(E_{\mathrm{p}}{ }^{\text {red }}=-2.31 \mathrm{~V}\right.$ vs. $\mathrm{Ag} / \mathrm{Ag}^{+}$in $\mathrm{CH}_{3} \mathrm{CN}$, ESI Fig. $4 \dagger$ ) to regenerate aryl radical $\mathbf{D}$ and propagate the radical chain. The SET process was strongly inhibited when the model reaction was performed with redox trap 1,4-dinitrobenzene ( 0.2 equiv., $42 \%$ after $6 \mathrm{~h}$ ), which confirmed the electron transfer propagation pathway. ${ }^{26}$ Another aspect to consider is the fate of the oxindole radical $\mathbf{C}$, which is an unproductive intermediate since it lies outside of the radical chain propagation cycle. We have obtained evidence that the radical $\mathbf{C}$ facilitated dimerization and dehydrogenation reactions in our system, since a trace amount of dimerization products 7 and $\mathbf{8}$ were detected in the gram scale experiment (ESI note $8 \dagger$ ). These results further demonstrate the SET process within the EDA complex.

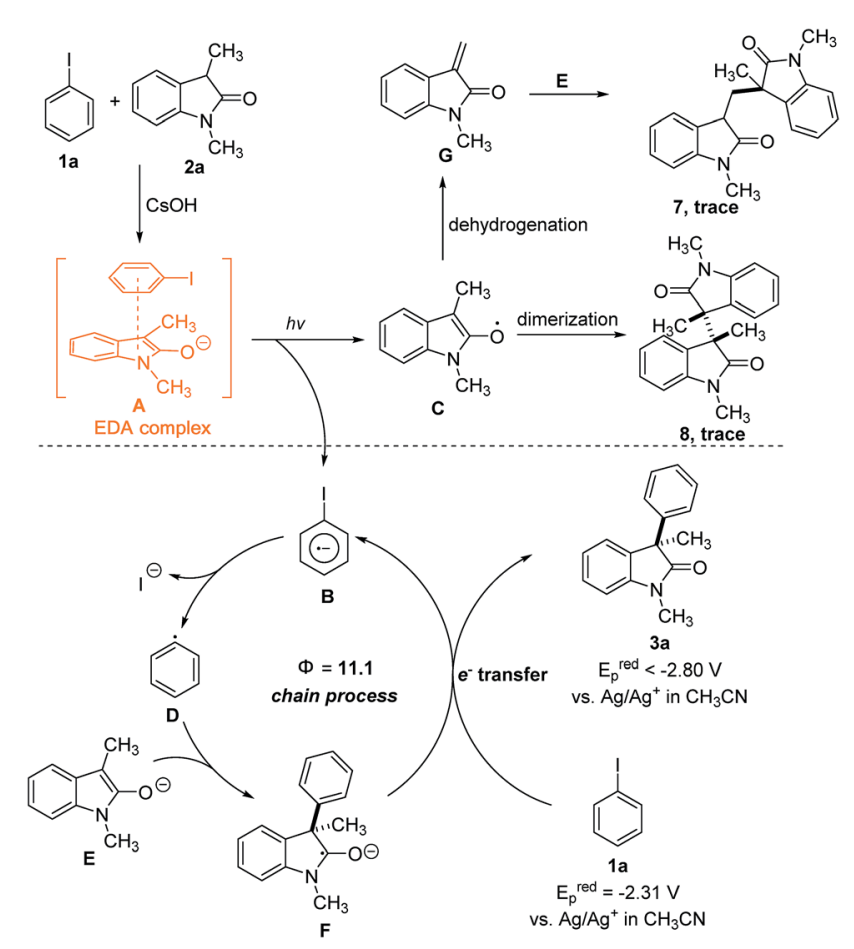

Scheme 1 Proposed mechanism for visible-light-promoted arylation. 


\section{Conclusions}

In summary, we have disclosed a transition-metal-free protocol for the $\mathrm{C}-\mathrm{C}$ cross-coupling of oxindoles and aryl halides under visible-light irradiation without the need for any external photoredox catalysts. The reactions were conducted at ambient temperature by using a household CFL bulb as the light source. Since no preactivation of the starting substrate is required and only the halogen anion is released as a byproduct, this transformation is highly atom- and step-economical. This new methodology offers a convenient and powerful synthetic tool for accessing 3-aryloxindole products under redox neutral conditions, and a wide range of 3-aryloxindole derivatives (33 examples) of pharmaceutical interest were constructed in a single step. The results of mechanistic experiments are consistent with a radical chain propagation pathway, wherein the aryl radical is generated by visible-light-induced electron transfer within the oxindole enolate-aryl halide EDA complex.

\section{Conflicts of interest}

There are no conflicts to declare.

\section{Acknowledgements}

We gratefully acknowledge the National Natural Science Foundation of China (21572236 and 21871228), the Natural Science Foundation of Yunnan Province (2018FY001015), and the Program for Changjiang Scholars and Innovative Research Team in University (IRT_17R94) for financial support. We are grateful to the Advanced Analysis and Measurement Center of Yunnan University for the help in NMR experiments.

\section{Notes and references}

1 (a) Z. Feng, L. Yun-Lin and Z. Jian, Adv. Synth. Catal., 2010, 352, 1381; (b) K. Shen, X. Liu, L. Lin and X. Feng, Chem. Sci., 2012, 3, 327; (c) J. S. Russel, in Heterocyclic Scaffolds II: Reactions and Applications of Indoles, ed. G. W. Gribble, Springer Berlin Heidelberg, Berlin, Heidelberg, 2010, p. 397, DOI: 10.1007/7081_2010_50.

2 A. Natarajan, Y. Guo, F. Harbinski, Y.-H. Fan, H. Chen, L. Luus, J. Diercks, H. Aktas, M. Chorev and J. A. Halperin, J. Med. Chem., 2004, 47, 4979.

3 K.-C. Luk, S.-S. So, J. Zhang and Z. Zhang, WO 2006136606A2, 2006.

4 P. Hewawasam, V. K. Gribkoff, Y. Pendri, S. I. Dworetzky, N. A. Meanwell, E. Martinez, C. G. Boissard, D. J. PostMunson, J. T. Trojnacki, K. Yeleswaram, L. M. Pajor, J. Knipe, Q. Gao, R. Perrone and J. E. Starrett, Bioorg. Med. Chem. Lett., 2002, 12, 1023.

5 (a) R. A. Altman, A. M. Hyde, X. Huang and S. L. Buchwald, J. Am. Chem. Soc., 2008, 130, 9613; (b) A. M. Taylor, R. A. Altman and S. L. Buchwald, J. Am. Chem. Soc., 2009, 131, 9900; (c) P. Li and S. L. Buchwald, Angew. Chem., Int. Ed., 2011, 50, 6396; (d) Z.-K. Xiao, H.-Y. Yin and L.-X. Shao, Org. Lett., 2013, 15, 1254; (e) M. J. Durbin and M. C. Willis, Org. Lett.,
2008, 10, 1413; $(f)$ P. K. Reddy Panyam, B. Ugale and T. Gandhi, J. Org. Chem., 2018, 83, 7622; (g) C.-K. Mai, M. F. Sammons and T. Sammakia, Org. Lett., 2010, 12, 2306.

6 Y. Jin, M. Chen, S. Ge and J. F. Hartwig, Org. Lett., 2017, 19, 1390.

7 J. Duan and F. Y. Kwong, J. Org. Chem., 2017, 82, 6468.

8 A. Vignesh, W. Kaminsky and N. Dharmaraj, ChemCatChem, 2017, 9, 910.

9 E. Koch, R. Takise, A. Studer, J. Yamaguchi and K. Itami, Chem. Commun., 2015, 51, 855.

10 H. R. Wu, H. Y. Huang, C. L. Ren, L. Liu, D. Wang and C. J. Li, Chem.-Eur. J., 2015, 21, 16744.

11 J. Guo, S. Dong, Y. Zhang, Y. Kuang, X. Liu, L. Lin and X. Feng, Angew. Chem., Int. Ed., 2013, 52, 10245.

12 S. Shirakawa, K. Koga, T. Tokuda, K. Yamamoto and K. Maruoka, Angew. Chem., Int. Ed., 2014, 53, 6220.

13 M. Sattar, V. Rathore, C. D. Prasad and S. Kumar, Chem.Asian J., 2017, 12, 734.

14 R. Samineni, C. R. C. Bandi, P. Srihari and G. Mehta, Org. Lett., 2016, 18, 6184.

15 (a) C. G. S. Lima, T. de M. Lima, M. Duarte, I. D. Jurberg and M. W. Paixão, ACS Catal., 2016, 6, 1389; (b) E. Arceo, I. D. Jurberg, A. Álvarez-Fernández and P. Melchiorre, Nat. Chem., 2013, 5, 750; (c) M. Nappi, G. Bergonzini and P. Melchiorre, Angew. Chem., Int. Ed., 2014, 53, 4921; (d) Ł. Woźniak, J. J. Murphy and P. Melchiorre, J. Am. Chem. Soc., 2015, 137, 5678; (e) Q. Guo, M. Wang, H. Liu, R. Wang and Z. Xu, Angew. Chem., Int. Ed., 2018, 57, 4747; $(f)$ C.-W. Hsu and H. Sundén, Org. Lett., 2018, 20, 2051; $(g)$ J. Wu, L. He, A. Noble and V. K. Aggarwal, J. Am. Chem. Soc., 2018, 140, 10700.

16 B. Liu, C.-H. Lim and G. M. Miyake, J. Am. Chem. Soc., 2017, 139, 13616.

17 (a) J. F. Bunnett, R. G. Scamehorn and R. P. Traber, J. Org. Chem., 1976, 41, 3677; (b) M. A. Fox, J. Younathan and G. E. Fryxell, J. Org. Chem., 1983, 48, 3109.

18 W.-T. Chen and W.-T. Wei, Asian J. Org. Chem., 2018, 7, 1429. 19 (a) Y. Y. Qian, K. L. Wong, M. W. Zhang, T. Y. Kwok, C. T. To and K. S. Chan, Tetrahedron Lett., 2012, 53, 1571; (b) J. N. Moorthy, A. L. Koner, S. Samanta, A. Roy and W. M. Nau, Chem. -Eur. J., 2009, 15, 4289; (c) L. J. Klein, D. G. Peters, O. Fourets and J. Simonet, J. Electroanal. Chem., 2000, 487, 66.

20 (a) D. E. Butler, R. F. Meyer, S. M. Alexander, P. Bass and J. A. Kennedy, J. Med. Chem., 1973, 16, 49; (b) B. Ren, C. Zhou and H. Wang, WO 2014173241A1, 2014.

21 S. V. Rosokha and J. K. Kochi, Acc. Chem. Res., 2008, 41, 641. 22 A. Bahamonde and P. Melchiorre, J. Am. Chem. Soc., 2016, 138, 8019.

23 P. MacCarthy, Anal. Chem., 1978, 50, 2165.

24 M. A. Cismesia and T. P. Yoon, Chem. Sci., 2015, 6, 5426.

25 M. Pichette Drapeau, I. Fabre, L. Grimaud, I. Ciofini, T. Ollevier and M. Taillefer, Angew. Chem., Int. Ed., 2015, 54, 10587.

26 (a) M. Nappi, G. Bergonzini and P. Melchiorre, Angew. Chem., Int. Ed., 2014, 53, 4921; (b) G. Filippini, M. Nappi and P. Melchiorre, Tetrahedron, 2015, 71, 4535. 